\title{
Curricular Integration and Measurement of Cultural Competence Development in a Group of Physical Therapy Students
}

\author{
Kerstin M. Palombaro ${ }^{1}$, Robin L. Dole², Jill D. Black ${ }^{3}$
}

\begin{abstract}
Introduction and Background

The link between cultural competence and effective physical therapy encounters is established. Physical therapist educational programs face the challenge of fostering the cultural competence of students in effective and meaningful ways within the curriculum. They also face the challenge of measuring the development of cultural competence to establish efficacy in the curriculum. One program measured the development of cultural competence in its students using the Inventory for Assessing the Process of Cultural Competence Among Healthcare Professionals-Student Version (IAPCC-SV) before and after the program's various educational opportunities immersed throughout the curriculum that could serve to increase cultural competency. In the three-year curriculum, the students participated in both mandatory and voluntary experiential learning opportunities. Required didactic presentations and activities were integrated throughout the curriculum and designed to enhance cultural competence. Voluntary experiences included providing service and/or leadership to a student-run pro bono clinic. The program was interested in whether cultural competency increased after these experiences and whether leadership opportunities or additional hours of voluntary service beyond the class median caused increases that exceeded the minimal detectable change $(M D C)$ reported in the literature.
\end{abstract}

\section{Methods}

All students completed the IAPCC-SV at the beginning of their Doctor of Physical Therapy education and again at the end of their final year of didactic curriculum.

\section{Results}

\footnotetext{
${ }^{1}$ Institute for Physical Therapy Education, Widener University, One University Place, Chester, PA 19013

${ }^{2}$ Institute for Physical Therapy Education, Widener University, One University Place, Chester, PA 19013
}

${ }^{3}$ Institute for Physical Therapy Education, Widener University, One University Place, Chester, PA 19013 
For the class of 2011, a Wilcoxon signed ranks test noted a significant increase in IAPCC-SV scores from pre-test $(56.51+/-4.82)$ to post-test $(64.16+/-6.19), p \leq .001$. For the class of 2012, a Wilcoxon signed ranks test noted a significant increase in IAPCC-SV scores from pre-test $(58.87+/-5.67)$ to post-test $(64.13+/-5.47), p \leq .001$. Sixteen students from the class of 2011 and 13 from the class of 2012 exceeded the 8.57point MDC of the IAPCC-SV.

\section{Discussion and Conclusion}

Exposure to a variety of cross-cultural encounters throughout a physical therapy curriculum significantly increases self-rating of cultural competence in these graduate students. Students who take advantage of volunteer leadership roles in extensive crosscultural encounters may be more likely to achieve an increase that exceeds the MDC on the IAPCC-SV. These results are particularly interesting given that the students themselves were ethnically homogeneous and did not experience cultural diversity within the constituents that made up their class or faculty.

\section{Key Words: Cultural Competence Curriculum, Measurement}

The increasingly diverse nature of client populations is well established (Humes, Jones, \& Ramirez, 2012), as is the impact one's culture has on physical therapy examination, evaluation, communication, interventions and outcomes (Lattanzi \& Purnell, 2006). Cultural competence is traditionally defined as, "a set of congruent behaviors, attitudes, and policies that come together in a system, agency, or among professionals and enables that system, agency or those professionals to work effectively in cross-cultural situations" (Cross, Bazron, Dennis, Isaacs, 1989). Leavitt (2010) asserts that the development of cultural competence within the physical therapy profession is mandated by the professional core values (American Physical Therapy Association (APTA), 2003), generic abilities (May, Morgan, Lemke, Karst, $\&$ Stone, 1995), and professional code of ethics (APTA, 2006). Specific to physical therapist student education, the Commission on the Accreditation of Physical Therapy Education (CAPTE), the sole accrediting body for entry-level physical therapist education in the United States (Commission on Accreditation in Physical Therapy Education, 2007), acknowledges the importance of developing cultural competence in students by including the phrase "culturally competent" in 26 of the current evaluative criteria. The American Physical Therapy Association created a "Blueprint for Teaching Cultural Competence" as a culmination task force report to assist faculty in this process (American Physical Therapy Association Committee on Cultural Competence, 2008). Thus, the importance of fostering cultural competence in physical therapist students is clear, as is the need to measure its development. How to best develop cultural competence in physical therapist students is also important to consider.

\section{Cultural Competency in the Professional Curriculum}

Panzarella (2009) states that weaving cultural competence throughout the curriculum sends an important message that this is a valued and necessary skill. This facilitates student recognition

Journal of the Scholarship of Teaching and Learning, Vol. 15, No. 5, October, 2015.

Josotl.Indiana.edu 
that cultural competence is not just of interest to one faculty member but valued by all faculty members as an important aspect of clinical practice (Panzarella \& Matteliano, 2008).

There are many ways in which physical therapy programs can infuse the message of cultural competence. Romanello (2007) describes a physical therapy program committed to the integration of cultural competence throughout the curriculum. She found that the program focused on creating a diverse campus environment, diverse clinical experiences, and a faculty committed to exploring diversity issues with students. Other examples include adding reflective practice as a curricular component as well as including public health content to provide students with additional skills to practice in diverse environments (Palombaro, Lattanzi, \& Dole, 2011). The Center for International Rehabilitation Research Information and Exchange (CIRRIE) provides a guide to assist programs with including cultural competence curriculum activities, such as case studies, classroom activities, and service-learning / community based projects (Panzarella \& Matteliano, 2008).

Service-learning and community based projects allow students to interact with community members in authentic contexts and have been shown to enhance professional competencies beyond clinical skills, including cultural competence (Reynolds, 2005). In one example Jorge (2006) describes a service-learning elective course where students work with local community farmers and ranchers with disabilities, exposing these students to farm and ranch culture. The students reportedly showed enhanced cultural competence in dealing with the farm and ranch culture (2006). Panzarella (2009) describes another example where students experience working through an interpreter and managing various cultural health beliefs and behaviors in the screening of local refugees. Evidence of formal assessment of cultural competence was not provided in this example, but helpful and positive information was gleaned from student exit interviews and course evaluations. Some curricular examples in the literature occur as single events where students engage with diverse populations (Black, 2002), while others describe ongoing or routine activities for student engagement (Palombaro, Lattanzi, \& Dole, 2011; Lattanzi \& Pechak 2011). An unfortunate but common theme among these examples is the challenge of measuring and documenting outcomes that support changes in cultural competence in the students who participate in these service-learning and community based projects.

\section{Measuring Cultural Competence}

From a pedagogical standpoint, measuring cultural competence outcomes is a necessary element to determine if the cultural competence curriculum is meeting its objectives (Panzarella, 2009). A systematic review that examined the literature on educational interventions to improve cultural competence in health care professionals from 1980 through 2003 reveals evidence in support of such training programs to improve knowledge, attitudes and skills of healthcare professionals (Beach et al., 2005). The majority of the 34 studies reviewed investigated training programs for physicians and nurses, most of which were pre-professional in nature. All studies reviewed included some level of pre-test/post-test or control group assessment.

Within physical therapy education, evidence of and changes in cultural competence in students has been assessed primarily through informal means. Wong and Blissett (2007) documented levels of cultural competence by analyzing reflective writings of student physical therapists using the Cultural Competence Curriculum (CCC). Two independent raters reliably Journal of the Scholarship of Teaching and Learning, Vol. 15, No. 5, October, 2015. 
applied the CCC, a 6-level ordinal scale from cultural destructiveness to cultural proficiency, across more than 150 written entries. Dupree and Goodgold (2007) describe an international cultural immersion program where the development of cultural competence was assessed by completion and analysis of a pre- and post-questionnaire lending insight into the cultural understandings that the participants gained. Panzarella (2009) described the use of standardized patients to allow students to practice skills related to cultural competence in a structured manner and to receive feedback about their performance in a patient examination activity.

The literature also includes examples of objective measurement tools used to evaluate cultural competence within physical therapy and health profession education. In their review of the relevant literature, Capell, Veenstra and Dean (2007) described several tools that have been used to measure cultural competence within the health care professions. The tools identified and appraised included the Cross-Cultural Adaptability Inventory (CCAI) (Kraemer \& Beckstead, 2003), the Cultural Competence Assessment (CCA), The Cultural Efficacy Scale (CSES) and The Inventory for Assessing the Process of Cultural Competence among Healthcare Professionals-Revised (IAPCC-R). Two of these tools, the CCAI and the IAPCC (specifically a version for students labeled the IAPCC-SV) have established reliability (Gulas, 2005; Kraemer \& Beckstead, 2003; Palombaro \& Lattanzi, 2012) for use with populations of physical therapist students (Gulas, 2005; Kraemer \& Beckstead, 2003; Palombaro \& Lattanzi, 2012). Hilliard, Rathsack, Brannigan and Sander (Hilliard, Rathsack, Brannigan, \& Sander, 2008) measured change in cultural competence of physical therapist students as a result of their clinical education experiences using the Cross-Cultural Adaptability Inventory (CCAI). Okere, Gleeson, Mitchell, Melzer and Olson (2012) used the Inventory for Assessing the Process of Cultural Competence among Healthcare Professionals-Student Version (IAPCC-SV) in a double-blind, randomized controlled trial to examine the differences in cultural competence between two groups of physical therapist students following specially designed instruction. They found statistically significant differences favoring the experimental group that participated in an educational module designed to enhance cultural competence compared to a control group that attended a professional abilities educational module. These findings support the use of the IAPCC-SV in documenting changes in student physical therapist cultural competence that may result from curriculum experiences designed to enhance cultural competence.

This paper describes the use of the IAPCC-SV as an objective measurement of the development of cultural competence in graduate physical therapy students from one accredited program after the required and voluntary educational opportunities integrated throughout the curriculum that could serve to increase cultural competence. The experiences designed to engage students and foster development of cultural competence included a combination of classroom activities and service-learning opportunities within the local community. Methods included didactic instruction, readings, discussion, case studies, reflective writing and self-assessment, and provision of clinical and health related services (Table 1). While all of the methods included in Table 1 are designed to help develop students' cultural competence, the experiences in the physical therapy student run pro bono clinic contributes much to this development. The clinic offers a consistent experience for cross-cultural encounters in a patient-care setting. Additionally only a small number of students are on the student board, thus engaging in hours of crosscultural encounters beyond what is integrated into the curriculum. 
Table 1. Curricular Activities to Enhance Cultural Competence Infused throughout the Curriculum

\begin{tabular}{|c|c|c|c|}
\hline Activity & Description & $\begin{array}{l}\text { Classroom or } \\
\text { Service-Learning }\end{array}$ & $\begin{array}{l}\text { Mandatory or } \\
\text { Voluntary }\end{array}$ \\
\hline $\begin{array}{l}\text { Classroom } \\
\text { Activities }\end{array}$ & $\begin{array}{l}\text { Cultural Self-Assessment } \\
\text { Community Self-Assessment }\end{array}$ & Classroom & Mandatory \\
\hline Case Studies & $\begin{array}{l}\text { Case studies with cultural diversity } \\
\text { throughout several courses }\end{array}$ & Classroom & Mandatory \\
\hline $\begin{array}{l}\text { Formal } \\
\text { Presentation }\end{array}$ & Lecture and Discussion & Classroom & Mandatory \\
\hline DVD Presentations & $\begin{array}{l}\text { Beyond the Vital Signs (Armstrong, } \\
\text { 2001) } \\
\text { Communicating Effectively } \\
\text { through an Interpreter (vanderHoof, } \\
\text { 1998) }\end{array}$ & Classroom & Mandatory \\
\hline $\begin{array}{l}\text { Medical } \\
\text { Ethnography } \\
\text { Reading \& } \\
\text { Reflection }\end{array}$ & $\begin{array}{l}\text { The Spirit Catches You and You } \\
\text { Fall Down (Fadiman, 1997) }\end{array}$ & Classroom & Mandatory \\
\hline $\begin{array}{l}\text { Annual MLK Day } \\
\text { of Service: } \\
\text { Community } \\
\text { Mobility Clinics }\end{array}$ & $\begin{array}{l}\text { First year students are paired with } \\
\text { third year students and conduct a } \\
\text { day of blood pressure screening and } \\
\text { mobility device cleaning \& } \\
\text { screening }\end{array}$ & Service-Learning & Mandatory \\
\hline $\begin{array}{l}\text { Community Health } \\
\text { Practicums }\end{array}$ & $\begin{array}{l}\text { Sustained weekly activity program } \\
\text { project conducted in collaboration } \\
\text { with } 4 \text { different community } \\
\text { partners }\end{array}$ & Service-Learning & Mandatory \\
\hline $\begin{array}{l}\text { Pro Bono Clinic } \\
\text { Service }\end{array}$ & $\begin{array}{l}\text { Service in the student-run physical } \\
\text { therapy pro bono clinic open } 4 \\
\text { evenings /week and staffed by } 4 \\
\text { student physical therapists each } \\
\text { evening; supervised by } 1-2 \text { licensed } \\
\text { physical therapists }\end{array}$ & Service-Learning & Voluntary \\
\hline $\begin{array}{l}\text { Pro Bono Clinic } \\
\text { Student Leadership }\end{array}$ & $\begin{array}{l}\text { Service on the leadership board } \\
\text { which consists of } 8-10 \text { student } \\
\text { leaders from each class (XXXXX, } \\
\text { 2011) }\end{array}$ & Service-Learning & Voluntary \\
\hline
\end{tabular}

The study also compares students who demonstrated increased service through provision of clinical services by participating as a student volunteer at the program's pro bono clinic or as a student leader of that clinic. Student leaders were those students that applied and were selected to serve on the pro bono clinic student leadership board. The model for this student-run pro bono clinic has been described in the literature (Palombaro, Lattanzi \& Dole, 2011). The purposes of

Journal of the Scholarship of Teaching and Learning, Vol. 15, No. 5, October, 2015.

Josotl.Indiana.edu 
this study were: 1) To determine if cultural competence increased at the end of the curriculum, 2) To determine if the increase was a meaningful change, 3) To determine if completing above a set threshold of clinic hours increased the likelihood of meaningful change, and 4) To determine if participation in pro bono clinic leadership resulted in an increased likelihood of meaningful change.

\section{Methodology}

The participants were members of the graduating classes of 2011 and 2012 for one accredited physical therapy program. The sole inclusion criterion was being a member of one of these two classes. This study was approved by the IRB of Widener University.

All students completed the Inventory for Assessing the Process of Cultural Competence among Healthcare Professionals-Student Version (IAPCC-SV) at the beginning of the physical therapy program. Table 1 depicts the curricular activities, both didactic and experiential, that were designed to enhance cultural competence across the three-year Doctor of Physical Therapy curriculum. All students completed the IAPCC-SV again at the end of their final year, just before going out for their final full-time clinical internship experience.

The measurement tool, the IAPCC-SV, measures cultural competence in the healthcare professional student, including physical therapy students. The 20-item IAPCC-SV measures constructs of cultural competence (Table 2) with scores ranging from 20-80 points with higher scores indicating increased competence. Students are assigned to levels of cultural competence based on their scores. The levels progress from culturally incompetent, culturally aware, culturally competent to culturally proficient (Campinha-Bacote, 2003). The IAPCC-SV is reported as reliable (Fitzgerald, Cronin, \& Campinha-Bacote, 2009; Palombaro \& Lattanzi, 2012) and valid (Fitzgerald et al., 2009) for use with health profession students and has a reported minimal detectable change (MDC) of 8.57 (Palombaro \& Lattanzi, 2012).

Table 2. Definitions of Constructs of Cultural Competence (Campinha-Bacote, 2007)

\begin{tabular}{|l|l|}
\hline Cultural Awareness & $\begin{array}{l}\text { "The deliberate self-examination and in-depth exploration of our } \\
\text { personal biases, stereotypes, prejudices, and assumptions that we } \\
\text { hold about individuals who are different from us (Campinha-Bacote, } \\
\text { 2007, p. 27)." }\end{array}$ \\
\hline Cultural Knowledge & $\begin{array}{l}\text { "The process of seeking and obtaining a sound educational base } \\
\text { about culturally diverse groups (Campinha-Bacote, 2007, p. 37)." }\end{array}$ \\
\hline Cultural Skill & $\begin{array}{l}\text { "The ability to collect relevant cultural data regarding the client's } \\
\text { presenting problem as well as accurately performing a culturally- } \\
\text { based physical assessment in a culturally sensitive manner } \\
\text { (Campinha-Bacote, 2007, p. 49)" }\end{array}$ \\
\hline Cultural Encounters & $\begin{array}{l}\text { "The act of directly interacting with clients from culturally diverse } \\
\text { backgrounds. (Campinha-Bacote, 2007, p. 71)" }\end{array}$ \\
\hline Cultural Desire & $\begin{array}{l}\text { "The motiviation of the healthcare professional to 'want to; engage } \\
\text { in the process of becoming culturally competent; not the 'have to" } \\
\text { (Campinha-Bacote, 2007, p. 21)." }\end{array}$ \\
\hline
\end{tabular}

Journal of the Scholarship of Teaching and Learning, Vol. 15, No. 5, October, 2015.

Josotl.Indiana.edu 
All students were assigned an identification number known only to one researcher (JB); another researcher (KP) performed the data analysis on the de-identified data. The identification number allowed for the IAPCC-SV pre- and post-tests to be linked. Demographics of sex, age and race were collected via the students' graduate school application file.

The number of volunteer hours in the clinic for each student and whether each student served as a clinic leader was also tracked and provided in de-identified format to the researcher performing the data analysis.

Data were analyzed using SPSS® Version 20. Following the instructions of the IAPCCSV authors (Fitzgerald et al., 2009), a composite score was calculated for each subject for preand post-test data and was entered into SPSS. Additionally, a change score for each subject was calculated in order to compare it to the MDC value. Descriptive statistics were used to characterize the study sample.

Wilcoxon signed ranks tests were performed on pre- and post-test data for each class cohort. Chi square analysis was performed on each class using the median number of clinic hours as a threshold and student board members versus non student board members to determine if clinic hours or student board service influenced attaining a meaningful change on the IAPCCSV.

\section{Findings}

\section{Demographics}

Seventy-nine students participated in this study. Thirty-nine were members of the class of 2011; 8 post-tests of the class of 2011 were considered incomplete because those students had neglected to complete the back of the page. Forty were members of the class of 2012; one presurvey and 2 post-surveys were incomplete for the class of 2012. See Table 3 for demographic information. The cohort was homogenous in ethnicity. This provided a unique opportunity to evaluate the improvement in cultural competence in an ethnically homogenous cohort of students. The ethnic and racial background of the cohort was in contrast to the communities served by the service-learning and pro bono clinical services provided by these students. The communities targeted for the activities and services are ones where the majority of the population is African-American, lower socio-economic conditions prevail, and the number of individuals that are underserved and uninsured is high (US Census 2005). The median and range of hours of clinic service for the entire class, student board, and non-student board members is reported as a point estimate of central tendency and variability respectively because the data was skewed. Many non-student board members in the class of 2011 performed no clinic service and several students were outliers in their number of service hours for both classes. The median is a stable estimate of central tendency as it is not influenced by outliers.

Table 3. Student Sample Demographics

\begin{tabular}{|l|l|l|}
\hline & Class of 2011 & Class of 2012 \\
\hline
\end{tabular}

Journal of the Scholarship of Teaching and Learning, Vol. 15, No. 5, October, 2015. 


\begin{tabular}{|l|l|l|}
\hline Number of Students & 39 & 40 \\
\hline $\begin{array}{l}\text { Average Age at } \\
\text { Graduation* }\end{array}$ & $26.48+/-2.9$ & $24.97+/-1.9$ \\
\hline Females & 25 & 27 \\
\hline Males & 14 & 13 \\
\hline Caucasian & 39 & 40 \\
\hline $\begin{array}{l}\text { Number of student } \\
\text { board members }\end{array}$ & 10 & 8 \\
\hline $\begin{array}{l}\text { Median hours of } \\
\text { clinic service entire } \\
\text { class* }\end{array}$ & $0(0-61)$ & $14.25(0-110.5)$ \\
\hline $\begin{array}{l}\text { Median hours of } \\
\text { clinic service } \\
\text { student board } \\
\text { members }\end{array}$ & $19.25(0-36)$ & $40.75(12-110.5)$ \\
\hline $\begin{array}{l}\text { Median hours of } \\
\text { clinic service for } \\
\text { non-student board } \\
\text { members }\end{array}$ & $0(0-61)$ & $7.5(0-43.5)$ \\
\hline
\end{tabular}

*Significant between-class differences $(\mathrm{p} \leq .01)$

\section{Findings}

Data from the class of 2011 and 2012 were analyzed separately as their experiences were different in terms of Clinic participation. For the class of 2011, the mean number of hours of participation was 9.47 (+/-16.66) and the median was 0 hours (range 0-61). For the class of 2012, the mean number of hours of participation was $18.71(+/-23.81)$ and the median was 14.25 hours (range $0-110.5$ ). The students in the class of 2011 primarily participated in the clinic if they were on the Student Board, whereas clinic participation was open to more students in the class of 2012. The majority of students who completed the pretest $(69.2 \%$ class of $2011 ; 53.8 \%$ class of 2012) scored in the culturally aware category while the majority of students who completed the post-test $(64.5 \%$ class of $2011 ; 73.7 \%$ class of 2012$)$ scored in the culturally competent category on post-test. The scores for the IAPCC-SV were normally distributed for both classes. See Table 4 for frequencies in all categories.

Table 4. Frequency Table for IAPCC-SV Cultural Competence Categories

\begin{tabular}{|l|l|l|l|l|l|}
\hline Category & IAPCC-SV Score & \multicolumn{2}{|l|}{$\begin{array}{l}\text { Number of Students } \\
\text { Pretest }\end{array}$} & \multicolumn{2}{l|}{$\begin{array}{l}\text { Number of Students } \\
\text { Posttest }\end{array}$} \\
\hline & & & & & \\
\hline
\end{tabular}

Journal of the Scholarship of Teaching and Learning, Vol. 15, No. 5, October, 2015.

Josotl.Indiana.edu 


\begin{tabular}{|l|l|l|l|l|l|}
\hline & & $\begin{array}{l}\text { Class of } \\
2011\end{array}$ & $\begin{array}{l}\text { Class of } \\
2012\end{array}$ & $\begin{array}{l}\text { Class of } \\
2011\end{array}$ & $\begin{array}{l}\text { Class of } \\
2012\end{array}$ \\
\hline Culturally Incompetent & $20-40$ & 0 & 0 & 0 & 0 \\
\hline Culturally Aware & $41-59$ & 27 & 21 & 9 & 9 \\
\hline Culturally Competent & $60-74$ & 12 & 18 & 20 & 28 \\
\hline Culturally Proficient & $75-80$ & 0 & 0 & 2 & 1 \\
\hline
\end{tabular}

For the class of 2011, a Wilcoxon signed ranks test noted a significant increase in IAPCC-SV scores from pre-test $(56.51+/-4.82)$ to post-test $(64.16+/-6.19)$ in the Class of 201 , $\mathrm{p} \leq .001$. For the 31 students in the Class of 2011 for whom linked pre-tests and post-tests were available, 16 exceeded the MDC of 8.57 points. Chi square analysis on completed data revealed differences between student board members and non-members in terms of exceeding the MDC of the IAPCC-SV at post-test $\mathrm{p} \leq .031$, with student board members exceeding the MDC at higher than the expected count. Because the median hours of service was 0 for this class, the median of 19.25 hours of service for the student board was used as a threshold for chi-square analysis to determine if being above the threshold of hours related to exceeding the MDC for the IAPCC-SV. Chi square analysis revealed no differences between being above the threshold of median hours of service and exceeding the MDC of the IAPCC-SV at post-test, $\mathrm{p} \leq .333$.

For the class of 2012, a Wilcoxon signed ranks test noted a significant increase in IAPCC-SV scores from pre-test $(58.87+/-5.67)$ to post-test $(64.13+/-5.47), \mathrm{p} \leq .001$. For the 38 students in the class of 2012 for whom linked pre-tests and post-tests were available, 13 exceeded the MDC of 8.57 points. Chi square analysis on completed data revealed no differences between student board members and non-members in terms of exceeding the MDC of the IAPCC-SV at post-test $\mathrm{p} \leq .695$. The median hours of service for this class of 14.25 was used as a threshold for chi-square analysis to determine if being above the threshold of hours related to exceeding the MDC for the IAPCC-SV. Chi square analysis revealed no differences between being above the threshold of median hours of service and exceeding the MDC of the IAPCC-SV at post-test, $\mathrm{p} \leq .819$.

\section{Discussion and Implications}

The results of this study demonstrate that an integrated curriculum that includes experiential learning and exposure to a variety of cross-cultural encounters throughout a physical therapy curriculum can significantly increase self-ratings of cultural competence in graduate students. In this study, students in the Class of 2011 who volunteered for leadership roles in a student-run pro bono clinic where they were engaging in cross-cultural encounters were more likely to achieve an increase that exceeded the MDC on the IAPCC-SV. This did not hold true for the Class of 2012. This class' leadership and commitment was not as strong as the class of 2011, requiring need for faculty mentorship, intervention and personnel changes. It may be that the findings for the Class of 2011 represented students with stronger leadership skills upon assuming the leadership positions. Strong leaders are able to work effectively with a variety of people, consider multiple perspectives, have strong self-awareness and have positive social exchanges and thus may be in a position to learn more from cross-cultural encounters (Avolio \& Gardner,

Journal of the Scholarship of Teaching and Learning, Vol. 15, No. 5, October, 2015.

Josotl.Indiana.edu 
2005). Students who are not strong leaders may be more focused on developing their leadership skills versus their cultural competence (Institute for Educational Leadership, 2005).

The IAPCC-SV identifies a continuum of the development of cultural competence and links the assessment scores to different levels of the continuum. These levels are culturally incompetent, culturally aware, culturally competent and culturally proficient (Campinha-Bacote, 2003). As noted above, there was an aggregate change of 6.6 points for the entire group denoting an improvement in cultural competence. The students shifted from the level of culturally aware toward culturally competent and culturally proficient. An improvement in IAPCC-SV scores indicates that the students are progressing toward cultural competence and cultural proficiency during the course of the curriculum.

Campinha-Bacote (2003) describes five constructs essential for the development of cultural competence for healthcare professionals: cultural awareness, cultural knowledge, cultural skill, cultural encounters, and cultural desire. In this study, all of the participants went through activities in the classroom designed to increase cultural awareness and cultural knowledge. Examples include completing a cultural autobiography, conducting and reflecting upon a cross-cultural interview, reading and discussing a medical ethnography, and working through culturally diverse client scenarios. In the experiential service-learning activities, the students regularly had cultural encounters and opportunities to apply their knowledge and grow in their awareness and skill. The students all had that opportunity but were not mandated to participate in the student-run physical therapy pro bono clinic on campus.

Students in one class who had served as student leaders of the student-led pro bono clinic for their three years in the program were more likely to exceed the MDC for the IAPCC-SV. Student leadership service is voluntary and is a commitment made in the first year of the program. It requires hours outside of class to both lead and serve in the pro bono clinic. Perhaps it is these students electing to volunteer in this way that are exhibiting inherent "cultural desire", the fifth construct of Campinha-Bacote's model and thus, experiencing more significant change in their scores. Campinha-Bacote describes cultural desire as the "motivation of the healthcare professional to "want to' engage in the process" of becoming cultural competent (2003)." The literature provides several examples where students electing to participate in service-learning experiences demonstrate improvements in cultural sensitivity or cultural competence (Dupree \& Goodgold, 2007; Hayward \& Charrette, 2012; Ng, Goddard, Gribble, \& Pickard, 2012).

As noted previously, the cohort in the study was unique in that it lacked ethnic diversity. This provided the opportunity to assess cultural competence development without ethnic diversity in the classroom. Romanello (2007) found that ethnic diversity in the classroom was an integral component to increasing cultural competence. This study shows that it is possible to make improvements in cultural competence even when the diversity is lacking in the classroom. While this is not ideal, it is encouraging to know that it is possible as the physical therapy profession continues to strive for a more diverse representation in the field, it is possible to enhance cultural competence in the ways described in this study.

This study's primary limitation was the use of a self-report measure to gauge cultural competence. In prior research the authors have questioned the reliability of student self-report of cultural competence because students early on in their exposure to cultures may overestimate their cultural competence (Palombaro \& Lattanzi, 2012). Students may be less able to accurately assess their cultural competence prior to exposure to cultures different than their own. Thus, student self-report may become increasingly reliable as students move through a physical therapy

Journal of the Scholarship of Teaching and Learning, Vol. 15, No. 5, October, 2015. 
curriculum by participating in multiple cultural encounters and opportunities to reflect on those encounters. The study also does not control for the individual clinical internship experiences that the students underwent throughout the curriculum. The first three clinical experiences occurred within the pre- and post-measure time frame. It is possible that the clinical internships in various settings largely contributed to improvements in cultural competence. It is also possible that experiences outside of the physical therapy curriculum contributed to growth.

Future study should include investigation into the student's experiences serving in leadership to this program's pro bono clinic to examine what aspects of that experience might lead to greater cultural competence. This would allow us to investigate whether students who struggle in leadership positions achieve the same level of cultural competence as those who do not and would also assist the program in incorporating similar experiences for all students. Investigating whether there is a threshold related to number of hours of service in the pro bono clinic associated with development of cultural competence would help this program plan for opportunities to promote cultural competence among its students. Additionally, tracking students at entrance to the program, at the program's midpoint and upon completion of the curriculum would allow for a better understanding as to whether students overestimate their cultural competence and then adjust their self-assessment after exposure to cross-cultural encounters. Finally, an investigation into other programs with opportunities for leadership and cross-cultural encounters may also yield additional information as to whether the actual experience, leadership opportunities imbedded into an experience or both have an impact on IAPCC-SV scores.

\section{Conclusion}

This study points to improvement in cultural competence scores pre and post a three-year curriculum that includes didactic classroom activities centered around cultural competence and emphasis on service learning and cultural encounters. Campinha-Bacote states, "cultural encounters is the pivotal construct of cultural competence that provides the energy source and foundation for one's journey towards cultural competence (2003)."

Curricular integration of cultural competence development including traditional classroom as well as community-based service-learning opportunities yielded improvements in cultural competence as measure by the IAPCC-SV tool. Increased exposure to service-learning and leadership opportunities provided these physical therapy students with the opportunity to improve their cultural competence in significant and measurable ways.

\section{References}

American Physical Therapy Association. (2003). Professionalism in Physical Therapy: Core Values. Retrieved January 5, 2015, from http://www.health.utah.edu/pt/clin_ed/ci_folder/Professionalism\%20Core\%20Values.pdf.

American Physical Therapy Association Committee on Cultural Competence. (2008). Retrieved January 5, 2015, from http://www.apta.org/educators/curriculum/apta/culturalcompetence.

Avolio, B.J. \& Gardner, W.L. (2005) Authentic leadership development: Getting to the root of positive forms of leadership. The Leadership Quarterly, 16(3), 315-338.

Journal of the Scholarship of Teaching and Learning, Vol. 15, No. 5, October, 2015.

Josotl.Indiana.edu 
Beach, M. C., Price, E. G., Gary, T. L., Robinson, K. A., Gozu, A., Palacio, A., Cooper, L. A. (2005). Cultural competence: A systematic review of health care provider educational interventions. Medical Care, 43(4), 356-373. http://www.ncbi.nlm.nih.gov/pmc/articles/PMC3137284/pdf/nihms297600.pdf

Black, J. D. (2002). Hands of hope: A qualitative investigation of a student physical therapy clinic in a homeless shelter. Journal of Physical Therapy Education, 16(2), 32-41.

Campinha-Bacote, J. (2003). The process of cultural competence: A culturally competent model of care ( $4^{\text {th }}$ Edition). Cinncinnati, OH: Transcultural C.A.R.E. Associates.

Campinha-Bacote, J. (2007) The process of cultural competence in the delivery of healthcare services: The journey continues. Cinncinnati, OH: Transcultural C.A.R.E. Associates.

Capell, J., Veenstra, G., \& Dean, D. (2007). Cultural competence in healthcare: Critical analysis of the construct, its assessment and implications. Journal of Theory Construction and Testing, 11(1), 30-37. http://connection.ebscohost.com/c/articles/32034402/cultural-competencehealthcare-critical-analysis-construct-assessment-implications

Code of ethics. (2006). ( No. HOD S06-09-07-12). Alexandria, VA: American Physical Therapy Association. Retrieved January 5, 2015, from http://www.apta.org/uploadedFiles/APTAorg/About_Us/Policies/HOD/Ethics/CodeofEthics.pdf

Commission on Accreditation in Physical Therapy Education. (2007). Evaluative criteria for accreditation of education programs for the preparation of physical therapists. Retrieved January 5, 2015, from http://www.apta.org/search.aspx?q=capte\%20criteria

Communicating effectively through an interpreter. vanderHoof, D. (Director). (1998).[Video/DVD] Seattle, WA: Cross Cultural Health Care Program.

Cross, T. L., Bazron, B. J., Dennis, K. W., \& Isaacs, M. R. (1989). A monograph on effective services for minority children who are severely emotionally disturbed. Washington, DC: National Technical Assistance Center for Children's Mental Health, Georgetown University.

Cross, T. L., Bazron, B. J., Dennis, K. W., \& Isaacs, M. R. (1989). Towards a Culturally Competent System of Care, Volume 1. Washington, DC: National Technical Assistance Center for Children's Mental Health, Georgetown University.

Dupree, A. M., \& Goodgold, S. (2007). Development of physical therapy student cultural competency through international community service. Journal of Cultural Diversity, 14(3), 126134. http://www.ncbi.nlm.nih.gov/pubmed/18314814

Fadiman, A. (1997). The Spirit Catches You and You Fall Down. New York, NY: Farrar, Straus, and Giroux.

Journal of the Scholarship of Teaching and Learning, Vol. 15, No. 5, October, 2015.

Josotl.Indiana.edu 
Fitzgerald, E. M., Cronin, S. N., \& Campinha-Bacote, J. (2009). Psychometric testing of the inventory for assessing the process of cultural competence among healthcare professionalsstudent version (IAPCC-SV). Journal of Theory Construction and Testing, 13(2), 64-68. http://connection.ebscohost.com/c/articles/44882145/psychometric-testing-inventory-assessingprocess-cultural-competence-among-healthcare-professionals-student-version-iapcc-sv

Gulas, C. J. (2005). Establishing the reliability of using the inventory for assessing the process of cultural competence among health care professionals with physical therapy students. (Unpublished Doctor of Philosophy). St. Louis University, St. Louis, MO.

Hayward, L. M., \& Charrette, A. L. (2012). Integrating cultural competence and core values: An international service-learning model. Journal of Physical Therapy Education, 26(1), 78-89. http://www.aptaeducation.org/members/jopte/i/2012/26/1/Hayward.pdf

Hilliard, M. J., Rathsack, C., Brannigan, P., \& Sander, A. P. (2008). Exploring the cultural adaptability of doctoral entry-level physical therapist students during clinical education experiences. Journal of Allied Health, 37(3), e199-220. http://www.ingentaconnect.com/content/asahp/jah/2008/00000037/00000003/art00015

Humes, K., Jones, N. A., \& Ramirez, R. R. (2012). Overview of race and hispanic origin: 2010. U.S.Census Briefs. http://www.census.gov/prod/cen2010/briefs/c2010br-02.pdf

Institute of Educational Leadership. (2005). Preparing and supporting diverse, culturally competent leaders: Practice and policy considerations. Retrieved from Eric Database. (ED493453)

Jorge, M. (2006). AgrAbility: Doctor of physical therapy (DPT) students learning to advocate for farmers and ranchers with disabilities. Journal of Physical Therapy Education, 20(3), 61-63. http://www.aptaeducation.org/members/jopte/adobepull.cfm?volumedate $=47$

Kraemer, T. J., \& Beckstead, J. (2003). Establishing the reliability of using the cross-cultural adaptability inventory with physical therapist students. Journal of Physical Therapy Education, 17, 27-32.

Lattanzi, J. B. \& Purnell, L. D. (Eds.). (2006). Developing cultural competence in physical therapy practice. Philadelphia, PA: F.A. Davis Company.

Lattanzi, J. B. \& Pechak, C. (2011). A conceptual framework for international service-learning course planning: Promoting a foundation for ethical practice in the physical therapy and occupational therapy professions. Journal of Allied Health, 40(2), 103-109.

Leavitt, R. (2010). Cultural competency: A lifelong journey to cultural proficiency. Thorofare, NJ: Slack, Incorporated.

Journal of the Scholarship of Teaching and Learning, Vol. 15, No. 5, October, 2015.

Josotl.Indiana.edu 
May, W. W., Morgan, B. J., Lemke, J. C., Karst, G. M., \& Stone, H. L. (1995). Model for ability-based assessment in physical therapy education. Journal of Physical Therapy Education, 9(1), 3-6.

Ng, P., Goddard, T., Gribble, N., \& Pickard, C. (2012). International placements increase the cultural sensitivity and competency of professional health students: A quantitative and qualitative study. Journal of Physical Therapy Education, 26(1), 61-68. http://www.aptaeducation.org/members/jopte/i/2012/26/1/Peiying.pdf

Okere, S. D., Gleeson, P., Mitchell, K., Melzer, B. A., \& Olson, S. L. (2012). The effects of a cultural competence education module on the cultural competence of student physical therapists: A double-blind, randomized controlled trial. Paper presented at American Physical Therapy Association Annual Conference and Exposition, Tampa, FL.

Palombaro, K. M. \& Lattanzi, J. B. (2012). Calculating the minimal detectable change for a cultural competency tool. PTJ-PAL, 12(1), J1-J7.

Palombaro, K. M., Lattanzi, J. B., \& Dole, R. L. (2011). A case report of a student-led pro bono clinic: A proposed model for meeting student and community needs in a sustainable manner. Physical Therapy, 91(11), 1627-1635. doi:10.2522/ptj.20100437

Panzarella, K. J. (2009). Beginning with the end in mind: Evaluating outcomes of cultural competence instruction in a doctor of physical therapy programme. Disability and

Rehabilitation, 31(14), 1144-1152. doi:10.1080/09638280902773745

http://www.ncbi.nlm.nih.gov/pubmed/19479532

Panzarella, K. J., \& Matteliano, M. A. (2008). In Stone J., \&Matteliano M. A. (Eds.), A guide to cultural competence in the curriculum: Physical therapy. Buffalo, NY: Center for International Rehabilitation Research Information and Exchange (CIRRIE). http://cirrie.buffalo.edu/culture/curriculum/guides/pt.pdf

Patient diversity: Beyond the vital signs. Armstrong, T. (Director). (2001).[Video/DVD] Carlsbad, CA: CRM learning.

Reynolds, P. J. (2005). How service-learning experiences benefit physical therapist student's professional development: A grounded theory study. Journal of Physical Therapy Education, 19, 41-51. http://connection.ebscohost.com/c/articles/17091040/how-service-learning-experiencesbenefit-physical-therapist-students-professional-development-grounded-theory-study

Romanello, M. L. (2007). Integration of cultural competence in physical therapist education. Journal of Physical Therapy Education, 21(1), 33-39.

United States Census (2005). Retrieved January 5, 2015, from http://quickfacts.census.gov/qfd/states/42/4213208.html. 
Palombaro' Dole' and Black

Wong, C. K., \& Blissett, S. (2007). Assessing performance in the area of cultural competence: An analysis of reflective writing. Journal of Physical Therapy Education, 21(1), 40-47.

http://www.aptaeducation.org/members/jopte/adobepull.cfm?volumedate $=48$

Journal of the Scholarship of Teaching and Learning, Vol. 15, No. 5, October, 2015.

Josotl.Indiana.edu 